\title{
When you hear the hoofbeats, sometimes it's the zebra
}

\author{
Michael J. Reardon, MD
}

\author{
From the Houston Methodist DeBakey Heart and Vascular Center, Houston, Tex. \\ Disclosures: Author has nothing to disclose with regard to commercial support. \\ Received for publication April 21, 2018; revisions received April 21, 2018; accepted for publication April 23, \\ 2018; available ahead of print June 12, 2018. \\ Address for reprints: Michael J. Reardon, MD, 6550 Fannin, Suite 1401, Houston, TX 77030 (E-mail: mreardon@ \\ houstonmethodist.org). \\ J Thorac Cardiovasc Surg 2018;156:e157 \\ $0022-5223 / \$ 36.00$ \\ Copyright (C) 2018 by The American Association for Thoracic Surgery \\ https://doi.org/10.1016/j.jtcvs.2018.04.114
}

Primary cardiac tumors are uncommon, occurring in approximately 1 of every 500 cardiac surgical cases. Approximately three quarters of primary cardiac tumors are benign, and one quarter are malignant. Of the malignant tumors, approximately three quarters are sarcoma. ${ }^{1}$ In contrast, secondary or metastatic tumors to the heart are 40 to 100 times more common. The general approach to benign tumors and primary cardiac sarcomas is surgical resection. However, metastatic tumors are rarely resected except for palliation of significant symptoms. The rarity of primary cardiac sarcoma and rare consideration of surgery for metastatic disease means few surgeons have appreciable experience in this area.

In this issue of the Journal, Zanobini and colleagues ${ }^{2}$ present an interesting and well-illustrated case of a 49-year-old man with metastatic urothelial cancer. Front-line therapy for metastatic urothelial cancer is chemotherapy. After 3 months of chemotherapy, transesophageal echocardiography was done showing a large, highly mobile mass filling much of the left atrium. The patient at this point had no symptoms consistent with this new mass. This leaves the surgical team conflicted. Could this be a clot in a patient with hypercoagulable cancer? Is this more metastatic urothelial cancer? Or finally, is this a new tumor of some type? The first decision would be clot versus tissue. This was settled by the cardiac magnetic resonance imaging, which nicely demonstrates tissue perfusion ruling against clot. The next decision is metastatic urothelial cancer versus new tumor and, if new, benign versus malignant. Imaging again plays a key role at least in separating benign from malignant. ${ }^{3}$ In this case, the limited point of origin and hypermobility could be either. On the basis of the imaging data that this represented a tumor of some sort, the heart team decided on resection. Even at this point, decisions remain for the surgeon. The team decided on a standard approach through the Waterston's groove. Complete resection was achieved, and a good recovery was realized. The surprise

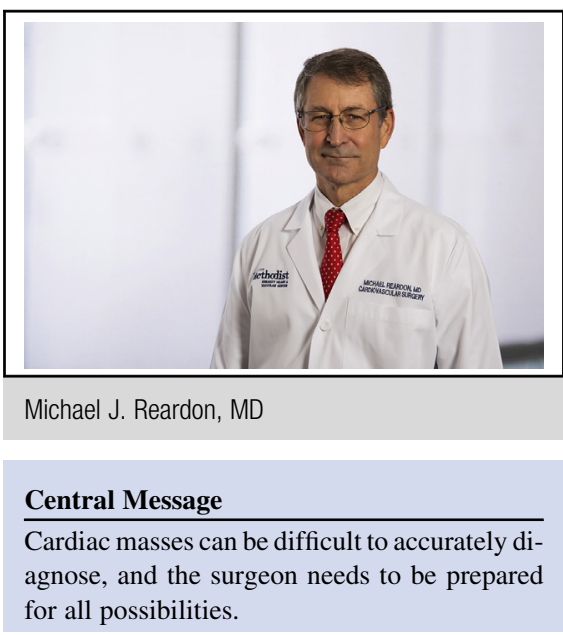

See Article page e153.

at this point was that the mass was a primary cardiac sarcoma, which is highly unusual. ${ }^{4}$ Unfortunately, not all large left atrial masses, and primary cardiac sarcomas are often among these, can be completely resected by this approach because of limited visibility. Surgeons undertaking these potentially challenging cases should be familiar with techniques such as cardiac autotransplantation and limited versions of this, such as division of the superior vena cava, aorta, and pulmonary artery, to fully open up the left atrium in case resection is difficult. ${ }^{5}$

I congratulate the authors on a good outcome in this challenging and unusual case and their well-presented case report. At the beginning of the case report, it would appear most likely that the mass would be a metastatic lesion. When you hear hoofbeats approaching, you are usually run over by horses. Occasionally, it is a zebra. Be prepared.

\section{References}

1. Bakaeen FG, Jaroszewski DE, Rice DC, Walsh GL, Vaporciyan AA, Swisher SS et al. Outcomes after surgical resection of cardiac sarcoma in the multimodality treatment era. J Thorac Cardiovasc Surg. 2009;137:1454-60.

2. Zanobini M, Travaglini S, Pepi M, Saccocci M. Primary tumor or metastasis? Extremely rare fibrosarcoma of the left atrial appendage. J Thorac Cardiovasc Surg. 2018;156:e153-6.

3. Cheema OM, Zarrin-Khameh N, Reardon MJ, Shah DJ, Little SH. Characterization of a cardiac mass using a systematic multimodality imaging approach. J Heart Lung Transplant. 2010;29:1080-1.

4. Ramlawi B, Leja MJ, Abu Saleh WK, Al Jabbari O, Benjamin R, Ravi V, et al. Surgical treatment of primary cardiac sarcomas: review of a single-institution experience. Ann Thorac Surg. 2016;101:698-702.

5. Ramlawi B, Al-Jabbari O, Blau LN, Davies MG, Bruckner BA, Blackmon SH, et al. Autotransplantation for the resection of complex left heart tumors. Ann Thorac Surg. 2014;98:863-8. 